\title{
Melatonin Induces Anti-Inflammatory Effects to Play a Protective Role via Endoplasmic Reticulum Stress in Acute Pancreatitis
}

\author{
Yina Chen ${ }^{\mathrm{a}}$ Jie Zhang ${ }^{\mathrm{b}}$ Qian Zhao ${ }^{\mathrm{a}}$ Qinfen Chen ${ }^{\mathrm{a}}$ Yangjie Sun ${ }^{\mathrm{a}}$ Yin Jin $^{\mathrm{a}}$ \\ Jiansheng $\mathrm{Wu}^{\mathrm{a}}$ \\ aDepartment of Gastroenterology, The First Affiliated Hospital of Wenzhou Medical University, \\ Wenzhou, 'Department of Neurology, Yuyao People's Hospital of Zhejiang Province, Yuyao, China
}

\section{Key Words}

Melatonin • Endoplasmic reticulum stress $•$ Inflammatory • Acute pancreatitis

\begin{abstract}
Background/Aims: Melatonin, which is mainly secreted by the pineal gland and released into blood, has anti-inflammatory properties in acute pancreatitis. Many studies show that melatonin can relieve inflammation in taurocholate-induced acute pancreatitis. However, the mechanisms of its anti-inflammatory effects are still undefined, especially the relationship between melatonin and endoplasmic reticulum stress. We explored the anti-inflammatory activity of melatonin in AR42J and rat models. Methods: The CCK-8 assay was used to assess effects of melatonin on AR42J cell viability. Inflammatory degree and the expressions of endoplasmic reticulum stress related molecules were examined by quantitative RT-PCR and western blotting. The degree of inflammation in the tissue was also accessed by pathological grading. Finally, we used the western blotting method to verify apoptosis and autophagy. Results: Endoplasmic reticulum stress was obviously activated in early stage inflammation in AR42J and rat models. Melatonin could induce anti-inflammatory effects via endoplasmic reticulum stress. Melatonin significantly inhibited inflammatory cytokines and the expression of ERS-related molecules. Finally, it played a protective role by promoting apoptosis and autophagy of the cells, which were damaged in the process of inflammatory reaction. Conclusion: Melatonin induces anti-inflammatory effects via endoplasmic reticulum stress in acute pancreatitis to play a protective role.

\section{Introduction}

The endoplasmic reticulum (ER) is one of the most important organelles in the cell body. When proteins are processed and modified in the wrong way, the ER plays a role in quality control by clearing proteins that are not folded or misfolded in the ER through the ubiquitinproteasome pathway (UPP), which is called ER-associated degradation (ERAD). External 
factor stimulation, such as oxidative stress, calcium ion imbalance, and lecithin synthesis disorder, can lead to excess proteins that are misfolded and gathered in the endoplasmic reticulum, causing endoplasmic reticulum stress (ERS). It is a self-protection mechanism against exogenous stress in early stages. ERS should increase folding ability of the ER, to address the damages to proteins, and then alleviate the burden of organelles by reducing the number of proteins in the endoplasmic reticulum. These effects are mainly implemented by unfolded protein response (UPR) [1]. In eukaryotes, the unfolded protein response is regulated by three types of endoplasmic reticulum-associated proteins such as inositol requiring enzyme 1 (IRE1a/b), protein kinase RNA-like ER kinase (PERK), and activating transcription factor $6(\mathrm{ATF} 6 \mathrm{a} / \mathrm{b})$. In the case of non-endoplasmic reticulum stress, the three proteins are combined with the endoplasmic reticulum chaperone protein, Bip/GRP78, to maintain the non-activated state of signal transduction. When the ER lumen is in its unfolded form of protein aggregation, resident chaperone proteins of the ER membrane cavity surface, leading to dissociation from the active binding site to the unfolded protein with partner protein separations, causes proteins associated with the ER membrane activation to start the UPR. When the endoplasmic reticulum damage is irreversible, and normal function cannot be resumed, the apoptotic signal is activated; the cell will eventually lead to programmed cell death or apoptosis. The endoplasmic reticulum stress-induced apoptosis is expressed in a variety of ways, including the expression and activation of ERS-related pro-apoptotic molecules such as chop and caspase-12, and pro-survival molecules such as gadd34 [2].

Inflammatory response is also one of the causes of ERS. Inflammation and infection lead to changes in the local environment and adjust ERS.

Acute pancreatitis (AP) is the result of the activation of trypsin in the pancreas caused by pancreatic tissue autodigestion, edemas, hemorrhages or even necrosis and inflammation. The pathogenesis of AP is not completely clear, at present, and the dominant theories are: the pancreatic self-digestion theory, the calcium overload theory of pancreatic cells, the inflammatory mediators theory, the apoptosis theory, and the intestinal bacterial translocation theory $[3,4]$. Pancreatic acinar cells with rich ER adapt to the physiological function for the synthesis of digestive enzymes, in which a variety of new synthetic digestive enzymes are transported to the ER. With the combination of BiP and ATP enzymatic activity, along with the energy consuming process of ATP hydrolysis, correct protein folding and post translation modification is promoted, along with packaging in the Golgi apparatus leading to extracellular zymogen granules secretion [5]. Recent studies have confirmed that UPR is involved in the injury and inflammatory reaction of the alveolar cells and promotes the development of AP. Kubisch reported that, in the early stage of the AP rat model induced by L-arginine, there were obvious pathological changes of ERS, and the expression of ERSrelated proteins, PERK, eIF2, ATF6, XBP1, BiP, chop, and caspase-12, was markedly increased [6]. Aurelia Lugea's study of the effects of alcohol on acute pancreatitis and the XBP1 gene showed that ERS was more sensitive in mice with the XBP1+/- gene knocked out compared toalcohol induced wild-type mice, inducing the formation of ATF6 and chop, which are associated with pancreatitis pathological change $[7,8]$. In addition, the pancreatic tissue also had an ERS reaction, such as endoplasmic reticulum stress in the intestinal epithelial cells, which were significantly activated, mainly in the expression of GRP78 in the mRNA and protein level up regulation [9]. Thus studies further demonstrate that ERS plays an important role in pancreatic gland injury and the induction of AP. Studies have shown that endoplasmic reticulum stress is closely related to the pro-inflammatory cytokines TNF- $\alpha$, IL- $1 \beta$, IL- 6 , and nuclear factor NF kappa B. They are the main causes for local damage of the pancreas and progression to systemic disease $[10,11]$. Apoptosis may also be produced in the late stage of ERS. It was suggested by foreign scholars in 2011 that the pancreatic acinar cell zymogen granule of selective autophagy, with degradation of abnormal activation of trypsinogen, has a role in the acute pancreatitis model [12].

Melatonin (MLT) is mainly secreted by the pineal gland, but the retina, tear ducts, and skin can also produce a small amount of MLT in mammals [13-15]. Moreover, Melatonin receptors are widely distributed. The receptors contain G protein coupling receptors and 


\section{Cellular Physiology Cell Physiol Biochem 2016;40:1094-1104 \begin{tabular}{l|l|l} 
and Biochemistry Published online: December 14, 2016 & $\begin{array}{l}\text { C } 2016 \text { The Author(s). Published by S. Karger AG, Basel } \\
\text { www.karger.com/cpb }\end{array}$
\end{tabular} \\ Chen et al.: Melatonin Induces Anti-Inflammatory Effects via Endoplasmic Reticulum Stress}

intracellular receptors and $\mathrm{G}$ protein coupling receptors in the human body are mainly MT1 and MT2 [16]. MLT is considered as a type of compound with a clinical application because of its biological functions such as improving sleep, anti-aging, regulating immunity, anti-tumor, and others [17-19]. Moreover, MLT inhibits mTOR-dependent autophagy in liver ischemia/reperfusion and protects the esophageal epithelial barrier through ERK1/2 signal transduction [20, 21]. In addition, MLT also has anti-oxidant and anti-inflammatory effects. Administering exogenous MLT shows anti-inflammatory effects via the NF- $\kappa B$ pathway [22]. Studies have found that MLT can cut off the NF- $\kappa B$ pathway in the asthma rat model's lung tissue. It also occurs in stress ulcers and inflammatory bowel disease.

However, it is still unknown whether melatonin shows anti-inflammatory effects via ERS. In this study, we demonstrated melatonin's potential role in controlling the ER stressassociated signaling pathway to reduces inflammation in SAP with both AR42J and rat models.

\section{Materials and Methods}

\section{Cell culture}

The AR42J cell line which was purchased from the American Type Culture Collection (ATCC, Manassas, VA, USA) was cultured in DMEM/high glucose (Gibco) with $20 \%$ fetal bovine serum (FBS, Sigma). The cells were incubated at $37^{\circ} \mathrm{C}$ under a humidified atmosphere of $5 \% \mathrm{CO}_{2}$. The nutrient solution was refreshed approximately every other day and the cells were passaged every 3-4 days.

\section{Cell Counting Kit-8 assay and cell morphological detection}

The Cell Count Kit-8 (CCK-8, Dojindo, Japan) was used to assess the effect of drugs on cell viability. AR42J cell suspension was seeded into 96 -well plates at $100 \mu \mathrm{l}$ per well $\left(1 \times 10^{4}\right.$ cells/well) and 6 -well plates at $2 \mathrm{ml}$ per well ( 1 x $10^{5}$ cells/well). After $24 \mathrm{~h}$, MLT was dissolved in fresh medium at different doses $(0.5,1$, and $2 \mathrm{mmol} / \mathrm{l})$, and the control and LPS group cells were incubated in culture medium. $1 \mathrm{~h}$ later, lipopolysaccharide was added into the groups of LPS and MLT $(0.5,1$, and $2 \mathrm{mmol} / \mathrm{l})$ at the dose of 10 $\mu \mathrm{g} / \mathrm{ml}$. In each 96-well plate, each group consisted of three parallel wells. After incubation for $0 \mathrm{~h}, 3 \mathrm{~h}$, $6 \mathrm{~h}, 12 \mathrm{~h}$, and 24 h, CCK-8 was added to the culture media, and then a plate reader (Infinite ${ }^{\circledR} 200$ PRO NanoQuant; Tecan Austria GmbH Untersbergstr, Austria) was used to measure the supernatants in each well at a wavelength of $450 \mathrm{~nm}$. Each experiment was performed in triplicate. Cell viability in each group was calculated as the absorbance. A six-well plate was used for cell morphological detection. After $24 \mathrm{~h}$ of treatment, we photographed the plate. Then, each well was washed twice with phosphate-buffered saline (PBS) and stained with Crystal Violet [23].

\section{Cell treatment}

AR42J cell suspension was seeded in 6-well plates at $2 \mathrm{ml}$ per well ( 5 x $10^{5}$ cells/well). After $24 \mathrm{~h}$, MLT was dissolved in fresh medium at different doses (0.5, 1, $2 \mathrm{mmol} / \mathrm{l})$ and the control group and LPS group cells were incubated in culture medium. One hour later, lipopolysaccharide was added at a dose of $10 \mu \mathrm{g} /$ $\mathrm{ml}$ into the LPS and MLT groups for $6 \mathrm{~h}$. Additionally, to discuss effects of lipopolysaccharide on the ERS pathway in different periods of functional treatment, the cells were treated with $10 \mu \mathrm{g} / \mathrm{ml} \mathrm{LPS} \mathrm{for} 0 \mathrm{~h}, 3 \mathrm{~h}, 6$ $\mathrm{h}, 12 \mathrm{~h}$ and $24 \mathrm{~h}$. All of these were prepared for quantitative RT-PCR and western blotting.

\section{Animals}

Eighteen clean-grade male Sprague-Dawley (SD) rats weighing 250 - 300 g were purchased from the Shanghai Slaccas Experimental Animal Limited Liability Company, Shanghai, China. The animals were maintained under standard conditions of 12-h light/dark cycles in a normal temperature-controlled room. Rats had access to standard rat pellets and watered libitum. All animals were deprived of rat pellets for $12 \mathrm{~h}$ before experimentation, but they were allowed free access to water throughout the experimental period. The experiment was approved by and performed on the basis of the guidelines for animal use of the Experimental Animal Center of Wenzhou Medical University. 


\section{Cellular Physiology Cell Physiol Biochem 2016;40:1094-1104

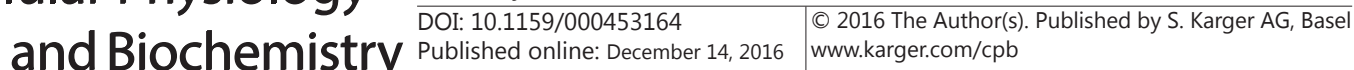 \\ Chen et al.: Melatonin Induces Anti-Inflammatory Effects via Endoplasmic Reticulum Stress}

\section{Animal groups and procedures}

SD rats were randomly assigned to a sham operation group (SO, $n=6)$, a severe acute pancreatitis group (SAP, $n=6$ ), and a melatonin treatment group (MLT, $n=6$ ). All rats were anesthetized by administration of $4 \%$ chloraldurate (0.7-0.8 ml/kg; Solarbio, Beijing, China). In the SAP and MLT groups, the biliopancreatic duct through the papilla was reached and cannulated by penetrating with a 24-gauge catheter after a microclip was used to clamp the hepatic duct. Acute pancreatitis was induced by $5 \%$ taurocholate (Sigma, St. Louis, MO, USA) through retrograde infusion of a dose of $1 \mathrm{ml} / \mathrm{kg}$ via a microinjection pump at a rate of $0.2 \mathrm{ml} / \mathrm{min}$. Rats in the SO group underwent the same surgery but without infusion. The MLT group was treated with 50 $\mathrm{mg} / \mathrm{kg}$ of melatonin (Sigma, St. Louis, MO, USA) intraperitoneal injection 30 min before the operation. After each operation, the abdomen was closed. All procedures were performed using sterile techniques.

At $6 \mathrm{~h}$ after SAP induction, rats were anesthetized with $4 \%$ chloral hydrate $(0.7-0.8 \mathrm{ml} / \mathrm{kg}$ body weight). The pancreatic tissues were harvested immediately, and then some of the tissue was placed in $40 \mathrm{~g} / \mathrm{L}$ paraformaldehyde and prepared for routine paraffin embedding prior to pathological examination. Other samples were stored at $-80^{\circ} \mathrm{C}$ for the determination of molecules related to ERS by real-time reversetranscription polymerase chain reaction (RT-PCR) and western blotting. The rats were euthanized by exsanguination after the experiments.

\section{Histological analysis and pathological scores of pancreatic tissues}

Samples of pancreatic tissues were fixed in $40 \mathrm{~g} / \mathrm{L}$ paraformaldehyde, dehydrated embedded in paraffin. Paraffin sections were cut into $4 \mu \mathrm{m}$ thick sections. Pancreas sections were stained with hematoxylin and eosin ( $\mathrm{H}$ and $\mathrm{E}$ ), and observed using light microscopy (Nikon, Tokyo, Japan). Tissues were examined by two experienced histologists who were blinded to the experimental protocol, using Schmidt's standards. The pancreatic sections, presenting a minimum of 6 fields, were examined for each sample and scored on a scale of 0-3 (0 being normal and 3 being severe) on the basis of edema, inflammatory cell infiltration, acinar cell degeneration, and parenchymal hemorrhage.

\section{Quantitative RT-PCR}

After treatment, the total RNA from cells and pancreatic tissues was isolated using Trizol reagent (Invitrogen), and cDNA was synthesized using Tiangen Reverse Transcriptase. The primers were synthesized by Sangon Biotech (Shanghai, China). The oligonucleotide sequences were as follows: GRP78:5'ATGCTGGCACTATTGCTGGACTGAA-3'(forward primer), 5'-CCA CAG TGT TCC TCG GAA TCA GTTT-3'(reverse primer); CHOP: 5'-AGA TGA AAT TGG GGG CAC CTA TATC-3'(forward primer), 5'-AGC ATG TGC ACT GGA GAT TAC TGCT-3'(reverse primer); Caspase12: 5'-CAA TCT ACA AGA TCA AAG GTT TGGC-3'(forward primer), 5'-CAA ACT TTT TGT TGC AGA TGA TGAG-3' (reverse primer); TNF- $\alpha$ : 5'-GTC GTA GCA AAC CAC CAAGC3'(forward primer), 5'-GAA GAG AAC CTG GGA GTA GAT AAGG-3' (reverse primer); $\beta$-actin: 5'-TGT CAC CAA CTG GGA CGATA-3'(forward primer), 5'-GGG GTG TTG AAG GTC TCAAA-3'(reverse primer).

\section{Western blot analysis}

Cultured cells and pancreatic tissues were homogenized in ice-cold RIPA buffer and PMSF for $30 \mathrm{~min}$ on ice. Then, the extracts were transferred to a microcentrifuge tube and centrifuged at $1.2 \times 10^{4} \mathrm{rad} / \mathrm{min}$ for $20 \mathrm{~min}$. The protein concentration was determined by the BCA assay (Beyotime). Equal amounts of total protein $(40 \mu \mathrm{g})$ were separately subjected to $12 \%$ SDS-PAGE and then transferred to PVDF membranes (BioRad, Hercules, CA, USA) at $170 \mathrm{~mA}$ for1-2 h. The membranes were blocked at room temperature for $2 \mathrm{~h}$ in blocking buffer (TBS, $0.1 \%$ Tween-20, and $5 \%$ nonfat milk) and then immunoblotted overnight at $4^{\circ} \mathrm{C}$ with primary antibodies targeted against the following: GRP78, CHOP, Caspase12, TNF- $\alpha$, Bcl-2, Bax, Caspase-3, P62, LC-3, GAPDH and $\beta$-actin (1:1000). After being washed three times with TBST for10 min each, the membranes were incubated for $1 \mathrm{~h}$ at room temperature with goat anti-rabbit or goat anti-mouse secondary IgG conjugated to horseradish peroxidase (HRP) (1:5000; Bioworld Technology Inc., Minnesota, USA) and then washed with TBST as before. Finally, the protein bands were visualized using a Western Bright ECL detection kit (Advansta, Menlo Park, California, USA). The density of specific bands was quantified using Image Lab software (Bio-Rad, Hercules, California, USA) with an imaging densitometer (Bio-Rad ChemiDoc MP, Hercules, California, USA). Using GAPDH or $\beta$-actin as an internal control, the blots were subjected to densitometry.

\section{KARGER}


Statistical analysis

Statistical analysis was carried out using the SPSS software (ver. 13.0; SPSS Inc., Chicago, IL, United States). All data are expressed as the mean \pm SD. Differences were considered significant at $\mathrm{p}<0.05$.

\section{Results}

Effects of melatonin on AR42J cell viability and cell morphological detection

AR42J cell viability was investigated using the CCK-8 assay. The LPS group had no statistical significance compared with the control group, but with the increase of the concentration of MLT, the cell viability decreased (Fig. 1A). The consumption of cell culture fluid also decreased (Fig. 1B). Cell viability was found to be significantly reduced after $24 \mathrm{~h}$ using $2 \mathrm{mmol} / \mathrm{l}$ melatonin and lipopolysaccharide (38\% viability, Fig. $1 \mathrm{~A}$ ).

Figure 1C displayed that the LPS group's cell morphological changes were not obvious. But the cells of MLT groups became short and round. The higher the concentration of MLT, the more obvious the morphological changes were.

Effects of lipopolysaccharide on endoplasmic reticulum stress pathway in different periods of functional treatment

The expression of molecules related to endoplasmic reticulum stress was examined by quantitative RT-PCR and western blotting in cells cultured with LPS for 0 h, 3 h, 6 h, 12 h, and $24 \mathrm{~h}$. Inflammation was increasingly severe with the passage of time. However, ERS-related molecule expression levels were increased significantly in the early stage of inflammation.

(A)

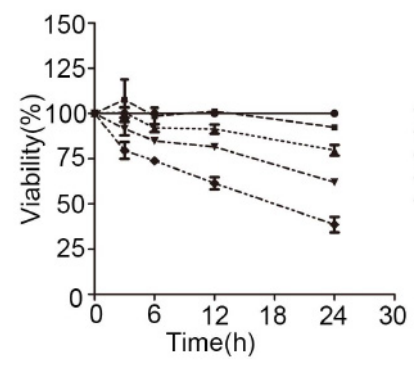

(B)

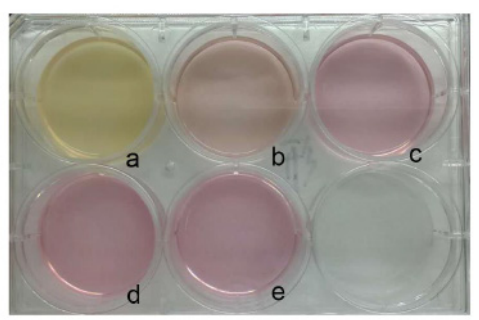

(C)

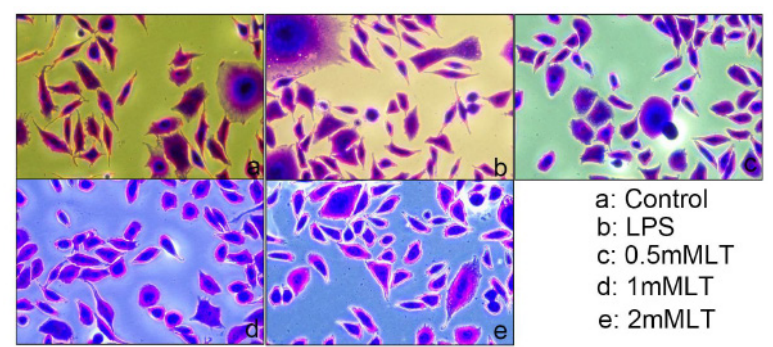

(Original magnification, $\times 400$ )

Fig. 1. Effects of melatonin on AR42J cell viability and cell morphological detection. (A) AR42J cells were treated for $0 \mathrm{~h}, 3 \mathrm{~h}, 6 \mathrm{~h}, 12 \mathrm{~h}$, and $24 \mathrm{~h}$. At $24 \mathrm{~h}$, the comparison between every two groups had statistical significance $(p<0.05)$. (B) The control group of cell culture change was the biggest, it became yellow. The higher the concentration of melatonin, the less obvious the change of cell fluid was. (C) Original magnification, $\times 400$. Cellular morphology of control was long spindle shape, but after treated with LPS, it became short and round. With MLT, cell morphological changes were more obvious. LPS: lipopolysaccharide; $0.5 \mathrm{mM}$ LT: $0.5 \mathrm{mmol} / \mathrm{l}$ melatonin + lipopolysaccharide; $1 \mathrm{mMLT}$ : $1 \mathrm{mmol} / \mathrm{l}$ melatonin + lipopolysaccharide; $2 \mathrm{mMLT}$ : $2 \mathrm{mmol} / \mathrm{l}$ melatonin + lipopolysaccharide. 


\section{Cellular Physiology and Biochemistry

Fig. 2. Effects of lipopolysaccharide on endoplasmic reticulum stress pathway in different periods of functional treatment. (A) Quantitative RT-PCR: GRP78: $\mathrm{P}<0.05$ ( $6 \mathrm{~h}, 12 \mathrm{~h}$ vs 0 h). CHOP: $p<0.05$ (6 h, 12 h, 24 h vs 0 h). Caspase12: p < 0.05(6 h, $12 \mathrm{~h}, 24 \mathrm{~h}$ vs $0 \mathrm{~h}$ ). TNF- $\alpha$ : p $<0.05$ (3 h, 6 h, 12 h, 24 h vs $0 \mathrm{~h}$ ). (B) Molecules related to endoplasmic reticulum stress expressions were examined by western blotting while cells were cultured with LPS for $0 \mathrm{~h}$, $3 \mathrm{~h}, 6 \mathrm{~h}, 12 \mathrm{~h}$, and $24 \mathrm{~h}$.
(A)
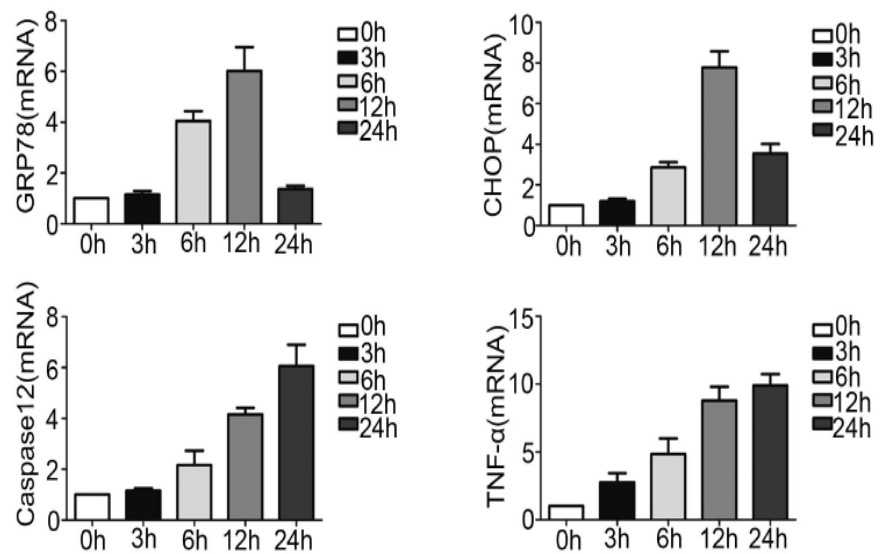

(B)

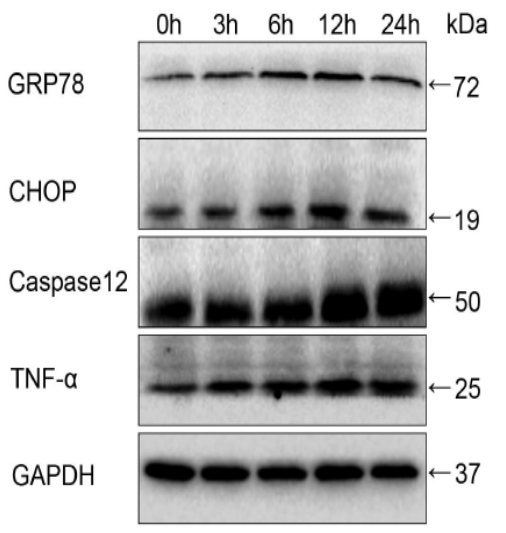

After a certain period of time, they would decline. However, caspase-12 was increased over time (Fig. 2).

Effects of melatonin of various concentrations on endoplasmic reticulum stress pathway

Quantitative RT-PCR and western blotting were applied to prove the effects of melatonin on ERS in the period of $6 \mathrm{~h}$. Figure 3 demonstrated that the expression of ERS-related factors of the LPS group was the highest of all the groups. Expression levels of these factors in the MLT groups were higher than the control group. It is possible that LPS could activate ERS. Furthermore, pre-treatment with MLT could relieve inflammation and restrain ERS. The extent of inhibition was likely to have a dose-dependence effect on melatonin concentrations.

\section{Effects of melatonin of various concentrations on apoptosis and autophagy} blotting.

Proteins related to apoptosis and autophagy expressions were detected by western

Figure 4 revealed that Bax and cleaved-caspase 3 of the LPS group increased significantly and the levels of Bcl-2 and pro-caspase- 3 were declined compared with the control group. The MLT groups were more obvious. In addition, under the condition of inflammation promoted apoptosis, treatment with MLT would aggrandize apoptosis compared with the group of LPS.

Figure 4 showed that the expression of P62 was reduced in groups in order from the left to right, which showed that autophagy increased in strength, and P62 was increasingly consumed. LC3-II/I increased in the LPS and MLT groups. They both showed that acute pancreatitis could activate the apoptosis and autophagy process of pancreatic acinar cells, while melatonin could enhance the effect of these two processes to protect cells. 
Fig. 3. Effects of melatonin of various concentrations on endoplasmic reticulum stress pathway. (A) Quantitative RT-PCR: GRP78: P $<0.05$ (control vs LPS, $0.05 \mathrm{mM}$ ). CHOP: $\mathrm{p}<0.05$ (control vs LPS, $0.05 \mathrm{mM}$; LPS vs $0.5,1,2 \mathrm{mM} ; 0.5$ vs $1,2 \mathrm{mM}$ ). Caspase12: $\mathrm{p}<0.05$ (control vs LPS, $0.05 \mathrm{mM}$; LPS vs $0.5,1,2 \mathrm{mM} ; 0.5 \mathrm{vs}$ 1, $2 \mathrm{mM}$ ). TNF- $\alpha: \mathrm{p}<0.05$ (control vs LPS, $0.05 \mathrm{mM}, 1 \mathrm{mM}$; LPS vs 0.5 , 1, $2 \mathrm{mM}$; 1 vs $2 \mathrm{mM}$ ). (B) Molecules related to endoplasmic reticulum stress expressions were examined by western blotting while cells were cultured with LPS and MLT for $6 \mathrm{~h}$. LPS: lipopolysaccharide; $0.5 \mathrm{mM}: 0.5$ $\mathrm{mmol} / \mathrm{l}$ melatonin + lipopolysaccharide; $1 \mathrm{mM}$ : $1 \mathrm{mmol} / \mathrm{l}$ melatonin + lipopolysaccharide; $2 \mathrm{mM}: 2 \mathrm{mmol} / \mathrm{l}$ melatonin + lipopolysaccharide.

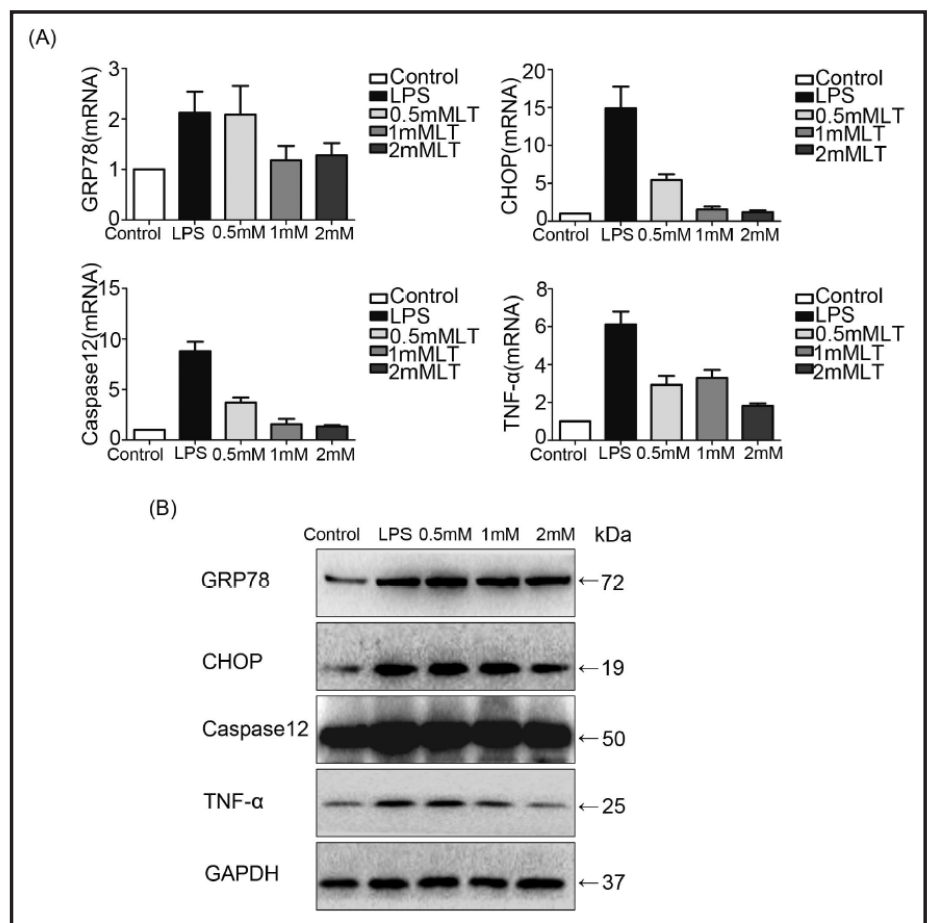

Fig. 4. Effects of melatonin of various concentrations on apoptosis and autophagy. The levels of Bax, Bcl-2, pro-caspase-3, cleaved-caspase-3, LC-3, P62 proteins were quantified by western blotting. LPS: lipopolysaccharide; $0.5 \mathrm{mM}$ : $0.5 \mathrm{mmol} / \mathrm{l}$ melatonin + lipopolysaccharide; $1 \mathrm{mM}: 1 \mathrm{mmol} / \mathrm{l}$ melatonin + lipopolysaccharide; $2 \mathrm{mM}$ : $2 \mathrm{mmol} / \mathrm{l}$ melatonin + lipopolysaccharide.

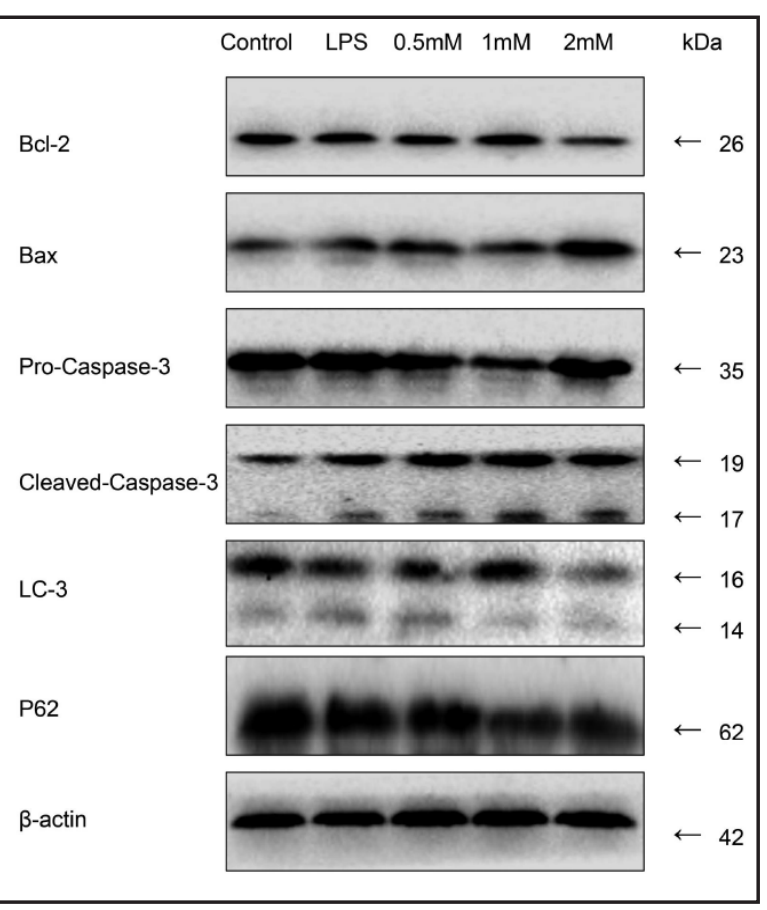

Effects of melatonin on pancreatic histopathology

Normal tissue morphology of the pancreas was observed in the SO group. Edema, parenchyma hemorrhage and inflammatory infiltration of neutrophils in pancreatic tissues were observed in the SAP group at $6 \mathrm{~h}$. While mild edema, parenchyma hemorrhage, and inflammatory infiltration of neutrophils in the pancreatic tissues were found in the MLT group (Fig. 5); therefore, the pathologic scores of pancreatic tissues declined considerably. The mean pathological scores for pancreatic tissues in the MLT group were significantly higher $(\mathrm{P}<0.05)$ than those for samples in the SO group $(5.33 \pm 0.52$ vs $0.33 \pm 0.52)$, but were significantly lower $(\mathrm{P}<0.05)$ than those for samples in the SAP group $(5.33 \pm 0.52$ vs7.17 \pm 0.75 ). 
Fig. 5. Effects of melatonin on pancreatic histopathology. The SO groups showed the normal structures of pancreas tissues at $6 \mathrm{~h}(\mathrm{HE} \times 40, \times 200)$. Pancreatic edema, parenchyma hemorrhage and neutrophils infiltration were observed in SAP groups at $6 \mathrm{~h}(\mathrm{HE} \times 40, \times 200)$. MLT group had more mildly edema, parenchyma hemorrhage and neutrophils infiltration $(\mathrm{HE} \times 40, \times 200)$. The pathologic scores of pancreas tissues were presented as mean \pm SD. $n=6$. SAP compared to the SO group, $\mathrm{P}<0.05$; Compared to the MLT group, $\mathrm{p}<0.05$. SO: sham operation group; SAP: severe acute pancreatitis group; MLT: melatonin treatment group.

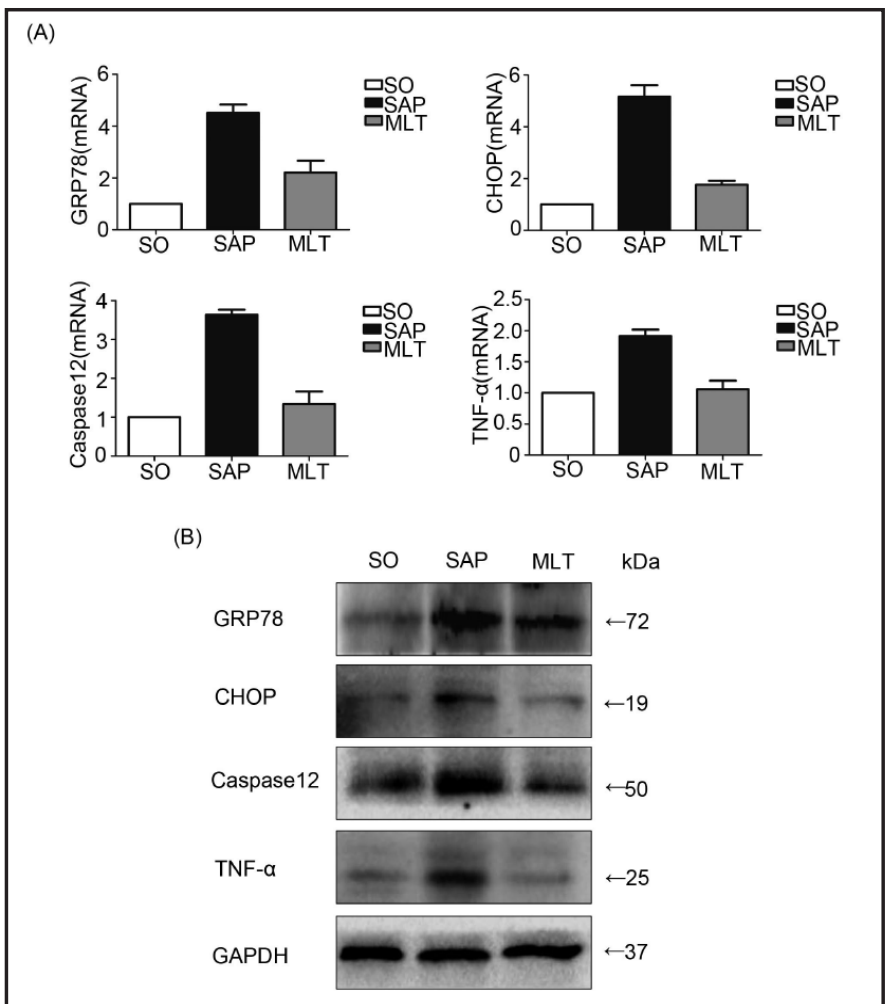

Fig. 6. Effects of melatonin on ERS in pancreatic tissues. (A) In GRP78, CHOP, Caspase 12 and TNF- $\alpha$, the SAP group compared to the SO group, $\mathrm{P}<$ 0.05; Compared to the MLT group, $\mathrm{p}<$ 0.05. (B) GRP78, CHOP, Caspase 12 and TNF- $\alpha$ were examined by western blotting in pancreatic tissues. SO: sham operation group; SAP: severe acute pancreatitis group; MLT: melatonin treatment group.

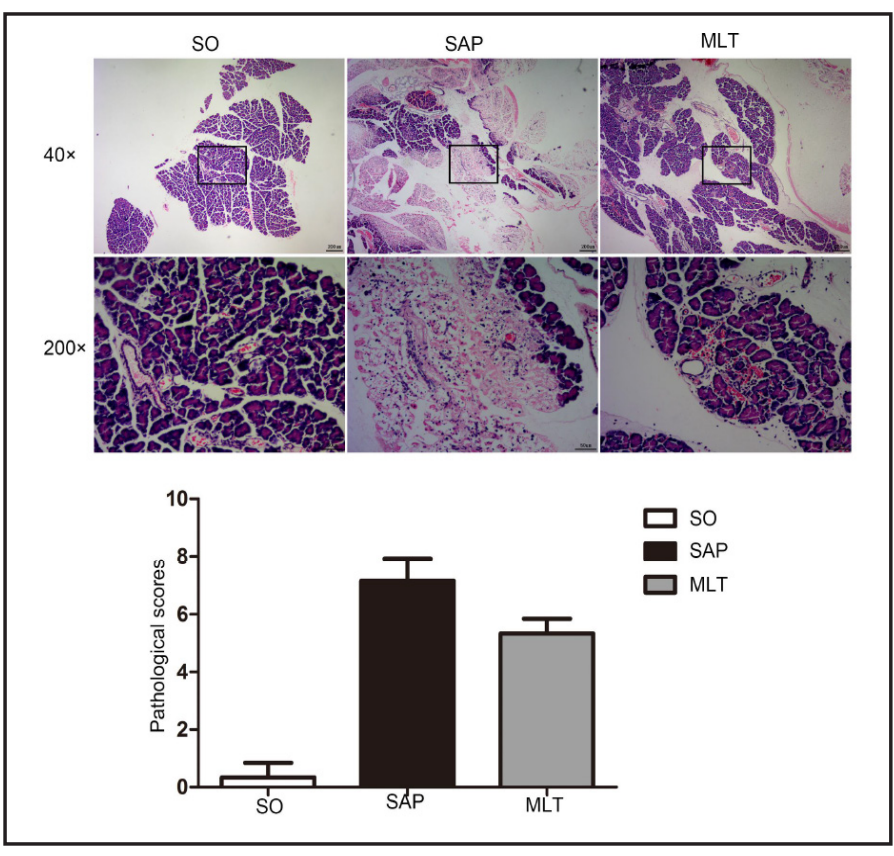

1101 


\section{Cellular Physiology Cell Physiol Biochem 2016;40:1094-1104 \\ \begin{tabular}{l|l} 
and Biochemistry & DOI: 10.1159/000453164 \\
Published online: 2016 The Author(s). Published by S. Karger AG, Basel \\
www.karger.com/cpb
\end{tabular} \\ Chen et al.: Melatonin Induces Anti-Inflammatory Effects via Endoplasmic Reticulum Stress}

\section{Discussion}

In our study, we demonstrated that melatonin could induce an anti-inflammatory effect via endoplasmic reticulum stress in AR42J and rat models. Endoplasmic reticulum stress was activated obviously in the early stage of AP inflammation. Melatonin significantly inhibited inflammatory cytokines and ERS-related molecular expression. Finally, it played a protective role by promoting apoptosis and autophagy of the cells that were injured in the inflammatory reaction process.

TNF is the most elevated cytokine and plays a central role in AP, which mediates local and systemic inflammatory responses in the pancreas. Our results in the study by RT-PCR and western-blotting, revealed the expression of TNF- $\alpha$ for AR42J and pancreatic tissues in the MLT group, which were significantly higher than those in the SO group, but were significantly lower than those in the LPS and SAP groups. The results showed that melatonin could effectively inhibit the inflammatory response in acute pancreatitis both in vivo and in vitro.

The early morphological changes of pancreatitis include the expansion of the endoplasmic reticulum and the loss of ribosomes and vacuoles. A study found that through pancreas tube retrograde taurocholic acid sodium salt injections for a few minutes, an acinar cell damage characteristic is endoplasmic reticulum cisternae particle formation [24]. This phenomenon is related to the occurrence of endoplasmic reticulum stress-related receptors IRE1, PERK, and ATF6, and its downstream pathways are activated [6]. In our experiment, GRP78, CHOP, and caspase-12 had higher expression in the MLT groups compared with the control group, but lower expression compared with the inflammatory group inAR42J, as also found in rat models. We hypothesize that inflammation can activate endoplasmic reticulum stress and MLT can inhibit ERS-related molecular expression to reduce inflammation in acute pancreatitis. This process may mainly occur in the early stages of acute pancreatitis.

$\mathrm{AP}$ is a local and systemic inflammatory response triggered by the death of pancreatic gland cells. Apoptosis is one of the main forms of cell death, which has specific morphological and biochemical characteristics [25]. Studies have shown that the use of supraphysiological doses of octapeptide CCK (cholecystokinin octapeptide, CCK-8) with the induction of pancreatitis, both in vitro and in vivo, activates caspase-8, caspase-9, and caspase-3, leading to apoptosis of pancreatic acinar cells in an experimental pancreatitis model [26]. Endoplasmic reticulum stress-induced apoptosis performance occurs in a variety of ways and is associated with both classical mitochondrial apoptosis pathways, including the specific caspase-12 pathway. A high expression of Bcl-2 anti-apoptotic protein can lead to antagonistic endoplasmic reticulum stress-induced apoptosis. Caspase-12 activation can induce apoptosis by activating caspase- 9 and caspase- 3 and is not dependent on the death receptor and mitochondrial pathway of apoptosis [27]. In AR42J, apoptosis of the LPS group occurred more often than that of the control group, while the MLT groups had a greater occurrence of apoptosis than that of the LPS group. It was also proved that melatonin could reduce inflammatory damage by enhancing an apoptotic effect. We hypothesized that apoptosis was related to the apoptotic factors associated with endoplasmic reticulum stress.

In acute pancreatitis, there is a large number of evident vacuoles in pancreatic gland cells [28]. Kouroku et al. have found that endoplasmic reticulum stress is induced by the PERKeIF2 $\alpha$ signaling pathway in mouse embryonic carcinoma cells [29]. In our study, autophagy in the LPS group was increased and was more obvious in the MLT groups. Fernandez et al. found that MLT could regulate autophagy and apoptosis through ERS [30]. Our research proved this point. Additionally, according to the experimental results, it was concluded that the effect of MLT was the enhancement of autophagy.

From our research and the above discussion, we can conclude that in acute pancreatitis, inflammation can activate ER stress, but melatonin can reduce inflammation through the inhibition of endoplasmic reticulum stress. At the same time, MLT can also stimulate apoptosis and autophagy to eliminate damaged cells to defend the body function. This discovery opens up a new therapeutic approach for clinical treatment of AP. In the future, 


\section{Cellular Physiology Cell Physiol Biochem 2016;40:1094-1104 \\ \begin{tabular}{l|l|l} 
DOI: 10.1159/000453164 & $\begin{array}{l}\text { O 2016 The Author(s). Published by S. Karger AG, Basel } \\
\text { www.karger.com/cpb }\end{array}$
\end{tabular} \\ Chen et al.: Melatonin Induces Anti-Inflammatory Effects via Endoplasmic Reticulum

we can focus on the development of drugs and methods that are targeted interventions for endoplasmic reticulum stress to further ease the symptoms of pancreatitis. It provides a reliable basis for the clinical treatment of acute pancreatitis. Furthermore, this experiment provides strong evidence for the treatment of acute pancreatitis with melatonin, which can be used in clinical practice as soon as possible.

\section{Acknowledgements}

This work was supported by two grants from the Science and Technology Bureau of Wenzhou, Zhejiang Province, China (2014S0192 and Y20150158) and the Public Projects of Zhejiang Province, China (No.2016C33215).

\section{Ethics}

The research reported was conducted in accordance with the ethical standards established by the United States National Institute of Health or its equivalent with respect to informed consent and the protection of human subjects.

\section{Disclosure Statement}

The authors declare no conflict of interest.

\section{References}

1 Boyce M, Yuan J: Cellular response to endoplasmic reticulum stress: a matter of life or death. Cell Death Differ 2006;13:363-373.

2 Hotamisligil GS: Endoplasmic reticulum stress and the inflammatory basis of metabolic disease. Cell 2010;140:900-917.

3 Song J-m, Liu H-X, Li Y, Zeng Y-J, Zhou Z-g, Liu H-Y, Xu B, Wang L, Zhou B, Wang R: Extracellular heat-shock protein 70 aggravates cerulein-induced pancreatitis through toll-like receptor-4 in mice. Chin Med J 2008;121:1420-1425.

4 Van Minnen L, Blom M, Timmerman H, Visser M, Gooszen H, Akkermans L: The use of animal models to study bacterial translocation during acute pancreatitis. J Gastrointest Surg 2007;11:682-689.

5 Low JT, Shukla A, Thorn P: Pancreatic acinar cell: new insights into the control of secretion. Int J Biochem Cell Biol 2010;42:1586-1589.

6 Kubisch CH, Sans MD, Arumugam T, Ernst SA, Williams JA, Logsdon CD: Early activation of endoplasmic reticulum stress is associated with arginine-induced acute pancreatitis. Am J Physiol Gastrointest Liver Physiol 2006;291:G238-G245.

7 Lugea A, Tischler D, Nguyen J, Gong J, Gukovsky I, French SW, Gorelick FS, Pandol SJ: Adaptive unfolded protein response attenuates alcohol-induced pancreatic damage. Gastroenterology 2011;140:987-997. e988.

8 Lugea A, Waldron RT, French SW, Pandol SJ: Drinking and driving pancreatitis: links between endoplasmic reticulum stress and autophagy. Autophagy 2011;7:783-785.

9 Zhao H-X, Fu X-S, Zhou X-Y, Chen X: Endoplasmic Reticulum Stress May Not Be Involved in Intestinal Epithelial Cell Apoptosis in Experimental Acute Pancreatitis. Dig Dis Sci 2015;60:1690-1698.

10 Norman J: The role of cytokines in the pathogenesis of acute pancreatitis. The Am J Surg 1998;175:76-83.

11 Pereda J, Sabater L, Aparisi L, Escobar J, Sandoval J, Viña J, López-Rodas G, Sastre J: Interaction between cytokines and oxidative stress in acute pancreatitis. Curr Med Chem 2006;13:2775-2787. 


\section{Cellular Physiology Cell Physiol Biochem 2016;40:1094-1104 \begin{tabular}{l|l} 
DOI: 10.1159/000453164 & $\begin{array}{l}\text { O 2016 The Author(s). Published by S. Karger AG, Basel } \\
\text { www.karger.com/cpb }\end{array}$
\end{tabular} \\ Chen et al.: Melatonin Induces Anti-Inflammatory Effects via Endoplasmic Reticulum Stress}

12 Grasso D, Ropolo A, Ré AL, Boggio V, Molejón MI, Iovanna JL, Gonzalez CD, Urrutia R, Vaccaro MI: Zymophagy, a novel selective autophagy pathway mediated by VMP1-USP9x-p62, prevents pancreatic cell death. J Biol Chem 2011;286:8308-8324.

13 Slominski A, Tobin DJ, Zmijewski MA, Wortsman J, Paus R: Melatonin in the skin: synthesis, metabolism and functions. Trends Endocrinol Metab 2008;19:17-24.

14 Hemadi M, Saki G, Shokri S, Ghasemi F: Follicular dynamics in neonate vitrified ovarian grafts after host treatment with melatonin. Folia Morphol 2011;70:18-23.

15 do Carmo Buonfiglio D, Peliciari-Garcia RA, do Amaral FG, Peres R, Nogueira TCA, Afeche SC, Cipolla-Neto J: Early-stage retinal melatonin synthesis impairment in streptozotocin-induced diabetic wistar rats. Invest Ophthalmol Vis Sci 2011;52:7416-7422.

16 Slominski RM, Reiter RJ, Schlabritz-Loutsevitch N, Ostrom RS, Slominski AT: Melatonin membrane receptors in peripheral tissues: distribution and functions. Mol Cell Endocrinol 2012;351:152-166.

17 Engler AC, Hadash A, Shehadeh N, Pillar G: Breastfeeding may improve nocturnal sleep and reduce infantile colic: potential role of breast milk melatonin. Eur J Pediatr 2012;171:729-732.

18 Carpentieri A, de Barboza GD, Areco V, López MP, De Talamoni NT: New perspectives in melatonin uses. Pharmacol Res 2012;65:437-444.

19 Yun M, Kim E-O, Lee D, Kim J-H, Kim J, Lee H, Lee J, Kim S-H: Melatonin sensitizes H1975 non-small-cell lung cancer cells harboring a T790M-targeted epidermal growth factor receptor mutation to the tyrosine kinase inhibitor gefitinib. Cell Physiol Biochem 2014;34:865-872.

20 Kang J-W, Cho H-I, Lee S-M: Melatonin inhibits mTOR-dependent autophagy during liver ischemia/ reperfusion. Cell Physiol Biochem 2014;33:23-36.

21 Tan J, Wang Y, Xia Y, Zhang N, Sun X, Yu T, Lin L: Melatonin protects the esophageal epithelial barrier by suppressing the transcription, expression and activity of myosin light chain kinase through ERK1/2 signal transduction. Cell Physiol Biochem 2014;34:2117-2127.

22 Forman K, Vara E, Kireev R, Cuesta S, Acuña-Castroviejo D, Tresguerres J: Beneficial effects of melatonin on cardiological alterations in a murine model of accelerated aging. J Pineal Res 2010;49:312-320.

23 Li W, Fan M, Chen Y, Zhao Q Song C, Yan Y, Jin Y, Huang Z, Lin C, Wu J: Melatonin Induces Cell Apoptosis in AGS Cells Through the Activation of JNK and P38 MAPK and the Suppression of Nuclear Factor-Kappa B: a Novel Therapeutic Implication for Gastric Cancer. Cell Physiol Biochem 2015;37:2323-2338.

24 Bhatia M, Neoptolemos J, Slavin J: Inflammatory mediators as therapeutic targets in acute pancreatitis. Curr Opin Investig Drugs 2001;2:496-501.

25 Granger J, Remick D: Acute pancreatitis: models, markers, and mediators. Shock 2005;24:45-51.

26 Sung K-F, Odinokova IV, Mareninova OA, Rakonczay Z, Hegyi P, Pandol SJ, Gukovsky I, Gukovskaya AS: Prosurvival Bcl-2 proteins stabilize pancreatic mitochondria and protect against necrosis in experimental pancreatitis. Exp Cell Res 2009;315:1975-1989.

27 Kalai M, Lamkanfi M, Denecker G, Boogmans M, Lippens S, Meeus A, Declercq W, Vandenabeele P: Regulation of the expression and processing of caspase-12. J Cell Biol 2003;162:457-467.

28 Gukovsky I, Gukovskaya AS: Impaired autophagy underlies key pathological responses of acute pancreatitis. Autophagy 2010;6:428-429.

29 Kouroku Y, Fujita E, Tanida I, Ueno T, Isoai A, Kumagai H, Ogawa S, Kaufman R, Kominami E, Momoi T: ER stress (PERK/eIF2 $\alpha$ phosphorylation) mediates the polyglutamine-induced LC3 conversion, an essential step for autophagy formation. Cell Death Differ 2007;14:230-239.

30 Fernández A, Ordóñez R, Reiter RJ, González-Gallego J, Mauriz JL: Melatonin and endoplasmic reticulum stress: relation to autophagy and apoptosis. J Pineal Res 2015;59:292-307. 